\title{
Erratum to: Strategy for Texture Management in Metals Additive Manufacturing
}

\author{
M.M. KIRKA ${ }^{1,2,3}$ Y. LEE, ${ }^{1,2}$ D.A. GREELEY, ${ }^{1}$ A. OKELLO, ${ }^{1,2}$ \\ M.J. GOIN ${ }^{1}$ M.T. PEARCE, ${ }^{1}$ and R.R. DEHOFF ${ }^{1,2}$ \\ 1.-Manufacturing Demonstration Facility, Oak Ridge National Laboratory, Knoxville, TN, USA. \\ 2.- Materials Science and Technology Division, Oak Ridge National Laboratory, Oak Ridge, TN, \\ USA. 3.—e-mail: kirkamm@ornl.gov
}

\section{Erratum to: JOM, Vol. 69, No. 3, 2017 DOI: $10.1007 / \mathbf{s 1 1 8 3 7 - 0 1 7 - 2 2 6 4 - 3}$}

In the published version of the paper, Eq. 2 (energy density of a spot melt) lacked the term associated with area of the electron beam necessary for the equation to yield volumetric energy density.
The corrected version is shown below and should be used. For reference, the experimental beam radius was assumed to be $80 \mu \mathrm{m}$ in the published work.

$$
E_{v}=\frac{i_{b} t_{o n} V}{z \pi r^{2}}
$$

